\title{
INFLUENCIA DE LA CONSTITUCIÓN DE CÁDIZ EN EL DERECHO CONSTITUCIONAL URUGUAYO
}

EDUARDO G. ESTEVA GALLICCHIO 
SUMARIO

1. INTRODUCCIÓN. 2. LA CONSTITUCIÓN DE CÁDIZ DE 1812: VIGENCIA EN MONTEVIDEO Y SU JURISDICCIÓN. 3. LA INFLUENCIA DE LA CONSTITUCIÓN DE CÁDIZ EN EL CONSTITUCIONALISMO URUGUAYO. 4. CONCLUSIONES 


\title{
INFLUENCIA DE LA CONSTITUCIÓN DE CÁDIZ EN EL DERECHO CONSTITUCIONAL URUGUAYO
}

\author{
EDUARDO G. ESTEVA GALLICCHIO*
}

\section{INTRODUCCIÓN}

La conmemoración del bicentenario de la Constitución de Cádiz es circunstancia propicia para recordar la notable influencia que la concepción doceañista ejerció en la formación del Derecho Constitucional uruguayo.

Es concepto unánimemente admitido por la doctrina uruguaya el reconocimiento de la importancia del Derecho Público Español en la estructuración del Derecho Público vernáculo.

Así, Justino E. JiméNEZ de ArÉCHAgA, el segundo en el tiempo de los Profesores de igual nombre que desempeñó la titularidad de la cátedra de Derecho Constitucional en la Facultad de Derecho de la Universidad de la República, consideró que «... el derecho, como concepto y como ley, es siempre condicionado por la historia, como lo han sido la justicia y la ética, este derecho político nuestro, afirmado en las leyes de la Revolución y en las horas primeras de la soberanía; ... nació condicionado por una tradición jurídica y un medio también ju-

* Director General del Centro de Documentación y Estudios Constitucionales del Uruguay. Catedrático de Derecho Constitucional en la Universidad de Montevideo. Presidente de la Sección Uruguaya del Instituto Iberoamericano de Derecho Constitucional. Presidente de la Asociación Uruguaya de Derecho Procesal Constitucional. Profesor en la Maestría en Derecho Constitucional y Derechos Humanos en la Facultad de Derecho de la Universidad Católica del Uruguay. Miembro Asociado de la Academia Internacional de Derecho Comparado. Antiguo Catedrático de Derecho Constitucional y de Derecho Público en la Universidad de la República. 
rídico y para hombres que, por motivo histórico, tenían un concepto propio de la moral y del derecho» ${ }^{1}$. Concluyó que «es de España que nos vienen el sentido de la libertad y el concepto del derecho» ${ }^{2}$.

Tiempo después, su hijo, Justino Jiménez de AréCHAGA, destacó la «poderosa originalidad» y el «hondo sentido liberal y democrático» que caracterizó al Derecho Público español ${ }^{3}$ y su trascendencia en la formación del Derecho constitucional uruguayo.

1.2. De allí que, por compartir las conclusiones precedentes, he sostenido que el Derecho Público español ha sido «fuente inspiradora por excelencia» del Derecho constitucional uruguayo ${ }^{4}$, desde las primeras formulaciones constitucionales de inspiración artiguista de $1813^{5}$, pasando por la llamada «pre Constitución» uruguaya, en otros términos, la Constitución ${ }^{6}$ dispersa y flexible que elaboró la $\mathrm{H}$.

${ }^{1}$ Cfr. Justino E. JimÉnEZ de ArÉCHAgA, Orígenes hispanos del Derecho de América, conferencia leída en 1925 en el Centro Gallego de Montevideo, en «Obras completas», Tomo I, «Temas Americanos», Montevideo, 1930, Barreiro y Ramos, pp. 92-93.

${ }^{2}$ Cfr. op. cit., p. 94.

${ }^{3}$ Cfr, Justino Jiménez de Aréchaga, Sobre Derecho Público Español, Centro de Estudiantes de Derecho, Montevideo, 1940.

${ }^{4}$ Cfr. Eduardo G. Esteva Gallicchio, Lecciones de Derecho Constitucional 2०, Historia constitucional del Uruguay, t. I, Serie Cursos y Manuales $N^{\circ} 5$ de la «Rev. Urug. de Der, Const. y Pol.», 2a . ed., Montevideo 1993, pp. 10-11.

${ }^{5}$ Hago referencia a varios documentos de interés constitucional, inspirados en el pensamiento de José ArTigas, fundador de la nacionalidad uruguaya. Entre otros: a) los pliegos de Instrucciones otorgadas a los Diputados que habrían de desempeñarse en la Asamblea Constituyente a reunirse en Buenos Aires en 1813 (los conocidos son: Instrucciones dadas por el ciudadano ArTigas el 13 de abril, por el Congreso reunido en Montevideo en fecha 5 de Abril de 1813 y por algunos Pueblos, casos de Santo Domingo Soriano el 18 de abril de 1813 y de San Fernando de Maldonado el 8 de julio de 1813; b) el proyecto de Constitución Federal de 1813 y c) el Proyecto de Constitución para la Provincia Oriental de 1813 (Cfr. sus textos, en E. G. Esteva Gallicchio, Documentos para el Estudio de la Historia Constitucional del Uruguay, ed. Ingranusi Ltda., Montevideo 1993 , pp. 71 y ss. y comentarios en Héctor Gros EsPiell, Esquema de la evolución constitucional del Uruguay, ed. Facultad de Derecho y Ciencias Sociales de la Universidad de la República, Montevideo, 1966, p. 18; Héctor Gros Espiell y Eduardo G. Esteva Gallicchio, Constituciones iberoamericanas / Uruguay, Instituto de Investigaciones Jurídicas - Universidad Nacional Autónoma de México, México 2005, pp. 6-7. También, E. G. Esteva Gallicchio, Lecciones ..., cit., t. 5; pp. 13 y ss.). Véase también el estudio de Jorge E. López RocCA, Influencia de la Constitución de Cádiz en el Constitucionalismo Rioplatense, en «La Constitución de Cádiz», Cuaderno $\mathrm{N}^{\circ} 1$ del Instituto de Derecho Constitucional de la Facultad de Derecho y Ciencias Sociales de la Universidad de la República, ed. F.C.U., Montevideo 1988, pp. 42-44.

${ }^{6} \mathrm{Cfr}$. Los documentos que forman esta Constitución flexible en E. G. Esteva Gallicchio, Documentos..., op. cit., t. I, pp. 311 y ss. y comentarios en Eduardo JiméNEZ DE ARÉCHAGA, La primera Constitución de nuestro Estado, en «Revista de Estudios Jurídicos y Sociales», año X-XI, N 67 , 
Sala de Representantes de la Provincia Oriental del Río de la Plata desde su instalación en 1825 hasta la entrada en vigor, el 18 de julio de 1830, de la primera Constitución codificada y rígida de Uruguay como Estado independiente.

Estimo posible concluir que la Constitución uruguaya de 1830 recibió una influencia decisiva del Derecho Público español y que dicha influencia, en tópicos sustanciales, subsiste tras las múltiples reformas constitucionales ${ }^{7}$.

\section{LA CONSTITUCIÓN DE CÁDIZ DE 1812: VIGENCIA EN MONTEVIDEO Y SU JURISDICCIÓN}

2.1. La Carta gaditana, en cuya elaboración participó formalmente el Diputado por Montevideo, capellán Rafael de ZufriATEGUI, fue publicada en Montevideo el 24 de septiembre de 1812 y jurada ${ }^{8}$ en esta plaza —último baluarte español en el Río de la Plata—, tres días después?

La actuación del Diputado montevideano no fue relevante en lo que atañe a la elaboración de la Carta $^{10}$.

Al tenor de los sucesos que se desarrollaban por entonces en la región, la vigencia efectiva fue efímera. Ello no obstante, es menester reconocer que los principios inspiradores de la Carta desarrollaron sólidas raíces ${ }^{11}$.

2.2. Luis B. MANZONI RuBio, ha señalado la similitud de coyunturas y de situaciones de las respectivas plazas, al ser jurada en marzo en Cádiz y en septiembre en Montevideo ${ }^{12}$

pp. 65 y ss.; H. Gros Espiell, Evolución..., cit. y E.G. Esteva Gallicchio, Lecciones..., op. cit. Véase el estudio citado de J. E. López RocCA, Influencia de la Constitución de Cádiz en el Constitucionalismo Rioplatense, en «La Constitución de Cádiz», cit., p. 44.

${ }^{7}$ De 1918, 1934, 1942, 1952, 1967 y 1997.

${ }^{8}$ Cfr.: María Emilia Pérez Santarcieri, Que todos griten: «; Viva la Pepa!» Montevideo y su primera Constitución española, en periódico «Lea», Montevideo 27 de septiembre de 1988.

${ }^{9}$ Cfr. Gustavo Gallinal, La Constitución española de 1812 en Montevideo, en «Revista del Instituto Histórico y Geográfico del Uruguay», t. I, pp. 517. Cf.: H. Gros Espiell, Evolución ..., op. cit., ed. 1966, p. 17 y nota 17; ed. 1991, p. 15-16 y nota 17.

${ }^{10}$ Formuló ante las Cortes de Cádiz, el 4 de agosto de 1811, la «Exposición sobre el Estado de Montevideo y su campaña»: cfr.: Archivo Artigas, Comisión Nacional Archivo Artigas, A. Monteverde y Cía, Montevideo MCMLXVI, t. IV, p. 360-369. Véase también Eduardo ACEVEDO, José Artigas Jefe de los Orientales y Protector de los Pueblos Libres / Su obra cívica / Alegato Histórico, El Siglo Ilustrado, t. I, Montevideo 1909, p. 152 y 276.

${ }^{11}$ Cfr: Francisco BauZÁ, Estudios constitucionales, Montevideo 1887, edición Colección de Clásicos Uruguayos, volumen 11, Montevideo 1953, pp. 25-26.

${ }^{12}$ Cfr. Antecedentes históricos de la Constitución española de 1812, en «La Constitución de Cádiz», Cuaderno $\mathrm{N}^{\circ} 1 \ldots$, op. cit., pp. 8. 
2.3. A la luz del tópico que me he propuesto, considero que no es procedente que ingrese al análisis de cuestiones sobre las que se ha abundado en el curso del ya bicentenario debate. Por ejemplo, si «las Cortes de Cádiz pretendieron hacer en España la Revolución francesa sin salir de los límites de la Asamblea Nacional Francesa», o si «quisieron hacer la revolución sin el pueblo» ${ }^{13}$; si se trataba de constituyentes «...conservadores con ideas más o menos revolucionarias» ${ }^{14}$; etc. Lo mismo acerca de si nos hallamos ante la mera recepción de la influencia francesa ${ }^{15}$ o de una labor restauradora de principios tradicionales del Derecho público español ${ }^{16}$.

Por lo contrario, estimo que corresponde asumir como premisa que, no obstante la efímera vigencia de la Carta gaditana, los principios sostenidos por los doceañistas calaron hondo en sectores cultos de la sociedad local montevideana, hoy uruguaya.

\section{LA INFLUENCIA DE LA CONSTITUCIÓN DE CÁDIZ EN EL CONSTITUCIONALISMO URUGUAYO}

3.1. Los autores que se ocuparon de las fuentes de la primera Constitución codificada y rígida de Uruguay de 1830 coincidieron en señalar la influencia que ejerció la Carta gaditana.

Asiste razón a Héctor Gros EsPIeLl cuando destaca que la Carta gaditana tuvo efectiva vigencia en Montevideo ${ }^{17}$, lo que implica que no nos hallamos solamente ante una fuente, sino frente a un precedente ${ }^{18}$.

Esta Carta, justo es recordarlo, fue una de las primeras Constituciones que, en el mundo, tuvieron expresión documental, con forma codificada y caracterizada por la nota de supralegalidad. En efecto, solamente fue precedida por la Constitución

${ }^{13}$ Cfr. Actas de las Cortes de Cádiz / Antología, Dirigida por Enrique Tierno Galván, Biblioteca Política Taurus, Madrid 1964, t. I, p. 10.

${ }^{14}$ Actas..., op. cit., t. I, p. 13.

${ }^{15}$ Cfr., por ejemplo, José Escobedo GonZÁlez AlBerú, Síntesis del proceso histórico-político europeo, Biblioteca de Derecho y de Ciencias Sociales, Madrid 1927, pp. 152 y ss.

${ }^{16}$ J. E. GonZÁlez Alberú, op. cit., pp. 169 y ss.

${ }^{17}$ Devenida sede de las máximas autoridades del Virreinato del Río de la Plata.

${ }^{18}$ Cfr.: Héctor Gros Espiell, La Constitución de Cádiz de 1812, la Constitución del Reino de Portugal de 1822, la Constitución del Imperio del Brasil de 1824 y la Constitución Argentina de 1826 como precedentes de la Constitución uruguaya de 1830, en «La Constitución de Cádiz de 1812 / Hacia los orígenes del constitucionalismo iberoamericano y latino», Actas del I Simposio Internacional, Cádiz 24 al 26 de abril de 2002, Coordinador Académico Asdrúbal Aguiar, ed. Universidad Católica Andrés Bello, Caracas, Venezuela, 2004, pp. 97 y $99 .$. 
estatal de Massachusetts de 1780, por la Constitución federal de Estados Unidos de 1787, por la francesa de 1791 y por el cuestionado Estatuto de Bayona de 1808.

3.2. Entre los autores que destacaron la influencia de la Carta de Cádiz, corresponde mencionar, entre otros, a Luis Melián LAFINUR ${ }^{19}$ y a Juan E. PIVEL DEVOTO $^{20}$. El segundo ha puesto de resalto que gran parte de la influencia francesa no fue directa, sino que se realizó «a través de la Constitución de Cádiz y de las distintas Constituciones americanas que desde 1811, ya habían adoptado y difundido aquellos principios políticos e institucionales» ${ }^{21}$.

Corresponde acotar que desde el proyecto de la Comisión de Constitución que luego aprobó la Asamblea Constituyente y que se transformara en la Carta de 1830 se advierte la influencia, en algunos artículos prácticamente literal, de la Constitución gaditana. En tal sentido es ilustrativo el cuadro comparativo incluido en la obra de Pivel Devoto ${ }^{22}$, en temas como objeto de las cárceles; establecimiento del orden y formalidades de los procesos; supuestos en que puede disponerse la libertad bajo fianza; organización de la Comisión Permanente; competencia de las Juntas Económico Administrativas en el ámbito local y reforma constitucional.

3.3. Dentro de la doctrina uruguaya merece ser destacado el prolijo estudio realizado por Jorge E. LóPEz RocCA, respecto de la influencia que ejerció la Carta de 1812 en la primera Constitución codificada y rígida de 1830, entre otros, en los temas principio de soberanía nacional, suspensión y pérdida de la ciudadanía, principio de separación de poderes, competencia de la Asamblea General, juicio político, varios tópicos sobre estatuto de los legisladores, en materia de atribuciones del Poder Ejecutivo, Disposiciones Generales que incluían soluciones en materia de derechos, etc. ${ }^{23}$.

3.4. En mi opinión, a doscientos años de la concepción doceañista, es necesario rescatar la influencia ejercida por determinados principios que en la Carta gaditana tuvieron recepción, ora expresa, ora implícita.

Bien dijo Justino Jiménez de Aréchaga que la Constitución de 1812, «...aún en estado de proyecto, ya circulaba por los pueblos americanos...» «Esta Constitución es una curiosa amalgama, como pudo señalarlo Argüelles, de antiguos y prestigiosos principios del liberalísimo, derecho medieval y de preceptos

\footnotetext{
${ }^{19}$ Cfr. El problema nacional y su solución inmediata, Montevideo 1905, pp. 70-71.

${ }^{20}$ Cfr.: Las ideas constitucionales del Dr. José Ellauri. Contribución al estudio de las fuentes de la Constitución uruguaya de 1830, Apartado de la «Revista Histórica», t. XXIII, Montevideo 1955, pp. 14-15.

${ }^{21}$ Cfr. Pivel Devoto, Las ideas...., op. cit., pp. 14-15.

${ }^{22}$ Idem, Anexo 8, pp. 107 y ss.

${ }^{23}$ Cfr. Influencia de la Constitución de Cádiz en el Constitucionalismo Rioplatense, en «La Constitución de Cádiz», Cuaderno N 1..., op. cit., pp. 45-47.
} 
de un nítido cuño francés. Será fuente de inspiración, casi permanente, para todos los ensayos de fórmulas constitucionales que se realicen en las antiguas colonias del Virreinato del Río de la Plata...» ${ }^{24}$.

La relevancia de la Constitución de 1812 para el Derecho uruguayo fue puesta de manifiesto, reitero, como fuente, pero también como precedente, por Héctor GRos ESPIELL ${ }^{25}$

\subsection{En tal sentido, estimo que los principales tópicos a recordar son}

\subsubsection{El contrato social ${ }^{26}$}

Surge implícitamente de diversos preceptos de la Carta gaditana (arts. 1, 13 en lo pertinente y concordantes) y fue recogido, aunque con matices derivados de la corriente contractualista adoptada, por todas las Constituciones uruguayas en sus respectivos artículos 1. Noción desarrollada por el art. $2^{27}$ de la Constitución de Cádiz, que presenta significativa coincidencia con los arts. $2^{28}$ y $3^{29}$ de las Constituciones uruguayas desde la de 1830 hasta la vigente.

\subsubsection{El principio de soberanía nacional ${ }^{30}$}

Expresamente afirmado por los arts. 3 («La soberanía reside esencialmente en la Nación, y por lo mismo pertenece a ésta exclusivamente el derecho de establecer sus leyes fundamentales») y concordantes de la Constitución de Cádiz y consagrado por todas las uruguayas (arts. 4: «La soberanía en toda su plenitud

${ }^{24}$ Cfr. La Constitución Nacional», ed. Medina, s./d., t. I, pp. 15-16; edición Cámara de Senadores, Montevideo 1992, t. I, p. 52.

${ }^{25}$ Cfr. La Constitución de Cádiz de 1812,.., op. cit., pp. 97 y ss.

${ }^{26}$ Cfr. Melchor Fernández Almagro, Orígenes del régimen constitucional en España, Colección Labor, v. IX, pp. 90-109, esp. P. 94, recordando la influencia de Francisco MARTínEZ MARINA.

${ }^{27}$ «La Nación española es libre e independiente, y no puede ser patrimonio de ninguna familia ni persona».

28 «Ella es y será para siempre libre e independiente de todo poder extranjero».

29 «Jamás será el patrimonio de personas ni de familia alguna».

${ }^{30}$ Cfr.: M. Fernández Almagro, Orígenes ..., op. cit.; Francisco Fernández Segado, Las Constituciones históricas españolas 4ª Ed., Civitas, Madrid 1992, pp. 70 y ss.; Jorge DE EsTeBAN, Estudio Preliminar a «Las Constituciones de España», Centro de Estudios Políticos y Constitucionales, Madrid 1997, p. 26-27; Milton R. Ruibal Dibello, Caracteres jurídicos e ideológicos de la Constitución española de 1812, en La Constitución de Cádiz, en «Cuaderno N 1 ...», op. cit., p. 24. 
existe radicalmente ${ }^{31}$ en la Nación, a la que compete el derecho exclusivo de establecer sus leyes, del modo que más adelante se expresará»; 82 y concordantes de la vigente).

\subsubsection{El principio de separación de poderes ${ }^{32}$}

Consagrado por los arts. 15 a 17, y concordantes de la de Cádiz, resulta de la conjugación de varios preceptos de las Constituciones uruguayas (arts. 72, 83, 149 y 233 y concordantes de la vigente).

\subsubsection{El individualismo $\mathrm{o}^{33}$}

El art. 4 de la Carta de 1812 dispuso que «la Nación está obligada a conservar y proteger por leyes sabias y justas la libertad civil, la propiedad y los demás derechos legítimos de todos los individuos que la componen», principio que ha sido reconocido y desarrollado por todas las Constituciones uruguayas (arts. 7, 10 y concordantes de la vigente).

\subsubsection{Principio de representación nacional ${ }^{34}$}

Reconocido por los arts. 27 y concordantes de la Constitución de 1812, fue admitido por todas las uruguayas.

\subsubsection{Principio de libertad ${ }^{35}$}

Reconocido por los arts. 4 y concordantes de la de Cádiz, ha sido admitido por todas las uruguayas (arts. 7, 10 y concordantes de la vigente).

${ }^{31}$ El Constituyente Miguel BARreIro propuso sustituir el vocablo «radicalmente» por «esencialmente», lo que acredita el conocimiento de la fórmula de la Constitución de Cádiz. Ello generó un importante debate (cfr.: Actas de la Asamblea General Constituyente y Legislativa del Estado, Montevideo 1896, Tipografía de la Escuela Nacional de Artes y Oficios, t.. I, pp. 429-431.

${ }^{32}$ Cfr. M. Fernández Almagro, Orígenes ..., idem; F. Fernández Segado, Las Constituciones..., op. cit.; J. De Esteban, Estudio Preliminar..., op. cit.; M. Ruibal Dibello, Caracteres jurídicos e ideológicos ..., op. cit., p. 25.

${ }^{33}$ Cfr. M. Fernández Almagro, Orígenes ..., ibidem.

${ }^{34}$ Cfr.: F. Fernández Segado, Las Constituciones..., op. cit., idem; J. DE Esteban, Estudio Preliminar.., idem; M. Ruibal Dibello, Caracteres jurídicos e ideológicos ..., op. cit., p. 28.

${ }^{35}$ Cfr.: F. Fernández Segado, Las Constituciones..., op. cit., ibidem. 


\subsubsection{Principio de igualdad ${ }^{36}$}

Resulta de diversos preceptos de la Constitución de 1812, arts. 248 con las excepciones resultantes de los arts. 249 y 250; y 258 y concordantes, fue reconocido por texto expreso por todas las uruguayas (arts. 7, 8 y concordantes de la vigente).

\subsubsection{Principio de confesionalidad del Estado ${ }^{37}$}

Solamente admitido por el art. 5 de la Constitución de 1830, aunque sin prohibir el ejercicio de otros cultos, y suprimido por la reforma constitucional que entró en vigor en 1919.

\section{CONCLUSIONES}

4.1. Los principios enunciados fueron recibidos por la Constitución uruguaya de 1830 y por todas las posteriores hasta la actualmente vigente, con excepción del último mencionado, que fue suprimido por la reforma constitucional de 1918 que consagró la separación entre el Estado y las diversas Iglesias.

4.2. Estimo posible sostener que esta influencia que se verificó en Uruguay, se advierte especialmente en materia de principios básicos o estructurales, especialmente los característicos del liberalismo ${ }^{38} \mathrm{o}$, si se quiere, del Derecho Constitucional liberal ${ }^{39}$.

Considero que para arribar a esta conclusión no es necesario demostrar la existencia de total coincidencia literal entre los textos doceañistas y la Constitución uruguaya que se examine, sino que basta con la concordancia conceptual.

4.3. El constitucionalismo uruguayo, entendiendo la expresión no solamente como la práctica de los Estados de darse Constituciones escritas, sino como la adopción de una forma de organización política moderna y racional, mucho debe a la Carta gaditana, independientemente de que ella haya ejercido in-

${ }^{36}$ Cfr.: F. Fernández Segado, Las Constituciones..., ibidem.

${ }^{37}$ Cfr.: F. Fernández Segado, Las Constituciones..., ibidem.

${ }^{38}$ Cfr., por ejemplo, Miguel A. Semino, La Constitución de Cádiz, en «Práctica constitucional», Fundación de Cultura Universitaria, Montevideo 1993, pp. 209-210.

${ }^{39}$ Véase, ampliamente, Héctor Gros Espiell, La Constitución de Cádiz en los orígenes del constitucionalismo liberal, en «Circunstancias / Artículos periodísticos / Entrevistas», Ediciones de la Banda Oriental, Montevideo, 2005, pp. 125-137. 
fluencia en forma directa o indirecta a través de otros textos constitucionales rioplatenses ${ }^{40}$ o de otros Estados ${ }^{41}$.

4.4. Tras más de ciento ochenta años de perfeccionamiento de la primera Constitución codificada de Uruguay, es posible aventurar que los referidos principios doceañistas tienden a forman parte de una suerte de edicto perpetuo constitucional uruguayo ${ }^{42}$, exclusivamente afectado durante los períodos de facto.

Sin embargo, tras la superación de los mismos, aquellos principios democráticos liberales clásicos decimonónicos fueron de inmediato restaurados, en los supuestos producidos durante el siglo XX, en 1934, 1942 y 1985.

Title:

INFLUENCE OF THE CONSTITUTION OF CADIZ IN THE URUGUAYAN CONSTITUTIONAL RIGHT

\section{Summary:}

1. INTRODUCTION. 2. THE CONSTITUTION OF 1812 CADIZ: USE IN MONTEVIDEO AND SU JURISDICTION. 3. THE INFLUENCE OF THE CONSTITUTION OF CADIZ IN THE URUGUAYAN CONSTITUCIONALISMO. 4. CONCLUSIONS

\section{Resumen:}

El artículo tiene por objeto estudiar la influencia de la Constitución de Cádiz de 1812 en el constitucionalismo uruguayo. La impronta liberal gaditana fue muy notable en los diferentes textos constitucionales que han jalonado la vida política y social de Uruguay desde 1830, primera Constitución, hasta nuestros días, de forma que tras más de ciento ochenta años de perfeccionamiento de la primera Constitución codificada de Uruguay, es posible aventurar que los principios doceañistas tienden a formar parte de una suerte de edicto perpetuo constitucional uruguayo exclusivamente afectado durante los períodos de facto.

\section{Abstract:}

The article intends to study the influence of the Constitution of Cadiz of 1812 in the Uruguayan constitucionalismo. Impronta liberal gadi-

\footnotetext{
${ }^{40}$ Caso de diversos Estatutos y textos constitucionales de las Provincias Unidas hasta la Constitución rivadaviana argentina de 1826.

${ }^{41}$ Por ejemplo, de la Constitución Chilena de 1828.

${ }^{42}$ Adopto una expresión utilizada por Justino JiménEZ DE ArÉCHAgA (nieto) con otro alcance, concretamente para referirse a los artículos de la Sección I de la Constitución.
} 
tana was very remarkable in different constitutional texts that they have laid out the political life and social of Uruguay from 1830, first Constitution, to the present time, so that after more than one hundred eighty years of improvement of the first codified Constitution of Uruguay, it is possible to venture that the doceañistas principles tend to de facto comprise of a luck of perpetual law exclusively affected Uruguayan constitutionalist during the periods.

Palabras clave:

Constitución de Cádiz, liberalismo, constitucionalismo uruguayo.

Key words:

Constitution of Cadiz, liberalism, uruguayan constitutionalism. 